\section{Estudo \\ CoDebate}

em Testã⿻

Dlanejamento
Revista Estudo \& Debate, Lajeado, v. 28, n. 4, 2021. ISSN 1983-036X

DOI: http://dx.doi.org/10.22410/issn.1983-036X.v28i4a2021.2941

\title{
IMPACTO ECONÔMICO NOS ESTADOS BRASILEIROS APÓS A RESOLUÇÃO DO SENADO FEDERAL No 13/2012
}

\author{
Keliany Bermudes Bahiense1, Francisco Antonio Bezerra ${ }^{2}$
}

\begin{abstract}
Resumo: Com a justificativa de acabar com a "Guerra Fiscal" o Senado Federal em abril de 2012 aprovou a Resoluçáo $\mathrm{n}^{\circ} 13$, unificando em $4 \%$ a alíquota de ICMS que incide sobre as operaçôes interestaduais de produtos importados. Percebe-se que existem dúvidas sobre a efetividade dessa resoluçáo no resultado econômico dos estados. Buscando preencher essa lacuna, esse estudo pretende analisar se após a implantação da Resolução do Senado Federal, que unificou a alíquota interestadual a 4\% de ICMS para comercializaçáo de produtos importados, ocorreu um impacto econômico negativo aos Estados concedentes de incentivos a importaçáo. O objetivo desse trabalho foi avaliar o impacto da unificação das alíquotas interestaduais de ICMS a 4\%, na situação econômica dos 13 Estados da Federaçáo que possuem incentivos a importaçáo, comparado aos outros 14 Estados da Federaçáo que não concedem incentivos semelhantes aos demais. $\mathrm{O}$ trabalho realizado foi de caráter exploratório e descritivo. Foi utilizado o modelo econométrico, denominado Diferences-in-Diferences que compara alteraçóes nas variáveis entre os Estados e entre os períodos, antes e após a Resolução 13/2012 do Senado Federal. Os dados evidenciam que após a medida, a variável PIB per capita, foi impactada negativamente nos estados que concedem incentivos fiscais e/ou financeiros.
\end{abstract}

Palavras-chave: Guerra Fiscal; Teoria Econômica; Incentivos fiscais; Resolução 13/2012 Senado Federal.

\section{ECONOMIC IMPACT IN BRAZILIAN STATES AFTER FEDERAL SENATE RESOLUTION No 13/2012}

\begin{abstract}
With the justification of ending the "Fiscal War", the Federal Senate in April 2012 approved Resolution No. 13, unifying the ICMS rate at $4 \%$ on the interstate operations of imported products. It is noticed that there are doubts about the effectiveness of this resolution on the economic results of the states. Seeking to fill this gap, this study aims to analise if after the implementation of the Federal Senate Resolution, which unified the interstate rate at $4 \%$ of ICMS for the commercialization of imported products, there was a negative economic impact on the states that grant import incentives. The objective of this work was to evaluate the impact of the unification of the interstate ICMS rates at 4\%, on the economic situation of the 13 States of the Federation that have incentives to import, compared to the other 14 States of the Federation that do not grant similar incentives to the others. The work performed was exploratory and descriptive. The econometric model, called Differences-in-Diferences, was used to compare changes in variables between states and between
\end{abstract}

\footnotetext{
1 Mestre em Ciências Contábeis.

2 Doutor em Controladoria e Contabilidade.
} 
periods, before and after Federal Senate Resolution 13/2012. The data show that after the measure, the variable GDP per capita, was negatively impacted in the states that grant tax and / or financial incentives.

Keywords: Fiscal War; Economic Theory; Tax breaks; Resolution 13/2012 Federal Senate.

\section{INTRODUÇÃO}

A constituição de 1988 criou um movimento concedendo aos Estados e municípios maior autonomia fiscal. Com isso, os Estados em busca de investimentos privados, começaram a disputar entre si, oferecendo benefícios às empresas para atrair novas sedes industriais (Nascimento, 2008, p. 211-237).

Essa disputa entre os estados é conhecida como "Guerra fiscal", por um lado essa disputa permitiu que os estados envolvidos gerassem emprego, aumentassem seu PIB, assim como, definiu o diferimento da arrecadação tributária (Nascimento, 2008, p. 678). Para Lima e Lima (2010, p. 558) essa disputa por investimento entre os estados se tornou a principal ferramenta de política de desenvolvimento, o que valorizou grandemente o desenvolvimento local, em prejuízo das demandas nacionais.

Com o propósito de por um fim, a "Guerra Fiscal" entre os Estados, o Senado Federal lançou, em 2012, a Resolução no 13 , estabelecendo, em substituição às alíquotas de $7 \%$ e $12 \%$, a alíquota única do ICMS de $4 \%$ para as operaçóes interestaduais de produtos importados ou com mais de 40\% em valor de insumo importado" (Lagemann, 2014, p. 122).

Para Macedo e Angelis (2013, p. 186) com a implantação da Resolução o governo pretendia acabar com os incentivos de redução do ICMS em Estados como Espírito Santo, Santa Catarina e Goiás. Essa redução de ICMS nesses Estados acabava beneficiando o mercado internacional, em detrimento do nacional. Além de impedir o crescimento da produçáo interna, ela também prejudicava a geraçáo de emprego em portos de outros Estados.

$\mathrm{Na}$ pesquisa de Santos e Machado (2011) foram analisados os 27 Estados da federação, 13 desses estados concediam algum tipo de incentivos direcionados à importação e os demais (14) Estados não foram encontrados nenhum tipo de incentivo.

O quadro atual motiva a análise deste estudo que avalia o impacto econômico gerado pela normativa, para todos os Estados concedentes de incentivos fiscais e ou/ financeiros. A pesquisa se faz necessária também para avaliar o efeito da medida, bem como, quais açóes os estados passaram adotar após a resolução para mitigar seus efeitos.

Alguns autores discutiram os efeitos da unificação das alíquotas interestadual, entretanto, não foi encontrado nenhuma pesquisa acadêmica que buscasse identificar os impactos econômicos causados nos Estados que concediam incentivos às empresas importadoras, após a Resoluçáo 13/2012. Para Lizote e Bidinha (2012, p. 8) a norma foi adotada para tentar evitar um prejuízo maior aos Estados, e controlar a entrada de mercadorias importadas no país, permitindo aos Estados, mesmo com a redução do ICMS, a continuarem com os incentivos a importação. Segundo os autores, o principal o objetivo desta norma seria enfraquecer as vantagens competitivas das mercadorias importadas diante 
das nacionais, diminuir a "Guerra Fiscal" e as diferenças de alíquotas interestaduais dos produtos importados.

Sabe-se que com as novas regras, os estados que se sentiram prejudicados mudaram suas estratégias para evitar grandes impactos negativos, um exemplo disso é a criação de um decreto determinando a antecipação da diferença do imposto do produto importado, prejudicando principalmente as empresas do Simples Nacional, que passaram a integrar esse elemento no custo, já que não podiam se creditar desse imposto. Outra consequência é que com a alíquota única para todos os Estados, as empresas importadoras passaram a analisar melhor os custos referentes ao transporte e outros atrativos nos sistemas portuários como a eficiência operacional e logística (Santos et al., 2013).

Conforme concluído por Joaquim (2011), a chamada "Guerra Fiscal” poderá chegar ao fim, com a medida que unificará as alíquotas. Entretanto, os custos de importar por São Paulo, ainda é muito alto, comparando com o Estado de Santa Catarina, por exemplo. Nesse exemplo, recolhe-se 3\% de ICMS em Santa Catarina e 21,95\% em São Paulo, há uma diferença bem significativa. É provável que o impacto da medida seja menor para as empresas que importam insumos e produzem nos Estados que subsidiam a importaçáo (Joaquim, 2011, p. 21).

Existem incertezas sobre a efetividade desta resolução e principalmente sobre o impacto no resultado econômico dos estados. Buscando preencher essa lacuna, este estudo pretende responder à seguinte questão: após a implantação da Resolução do Senado Federal, que unificou a alíquota interestadual a $4 \%$ de ICMS para comercialização de produtos importados, ocorreu um impacto econômico negativo aos Estados concedentes de incentivos a importação?

Diante deste contexto, o objetivo desse trabalho foi avaliar o impacto da unificação das alíquotas interestaduais a 4\% de ICMS para produtos importados na condição econômica dos Estados quando comparado a Estados sem incentivos fiscais e/ou financeiros.

Os resultados dessa pesquisa indicam que, após a resolução 13/2012, o PIB foi impactado negativamente nos estados que concedem incentivos à importação, embora tenha ocorrido um aumento no PIB em comparaçáo aos períodos anteriores, quando comparado ao grupo de controle, percebe-se que esse crescimento foi menor do que o percebido no grupo de controle, estados sem incentivo.

\section{REFERENCIAL TEÓRICO}

\subsection{TEORIA ECONÔMICA}

A teoria econômica é a ciência do mercado gerido pelo Estado. Da mesma forma que não faz sentido um mercado sem um Estado para comandar, não faz sentido uma teoria econômica sem o Estado administrando e garantindo o mercado (Pereira, 2009).

De acordo com Barquero (2002, p. 29), a economia política local está integrada a uma abordagem de baixo para cima da política de desenvolvimento, nela são executadas e controladas as açóes realizadas pelos administradores locais, que formam grupos ou órgãos 
direcionados à conhecer a estratégia do sistema produtivo local, assim como, consolidar as ideias propostas e colocar em prática as açôes que compóem a estratégia local de desenvolvimento.

No mesmo sentido, conforme Souza (2005), para uma regiáo se desenvolver não depende apenas dos investimentos do governo federal e da instalação das grandes empresas motrizes, depende também do desenvolvimento das regióes menores, da infraestrutura interna, do movimento das forças locais, formada pelos empresários, universidades, prefeituras e do governo do estado.

Ainda na visão de Souza (2005), o crescimento têm sido desigual em diversos países, provocando fortes migraçôes de várias regióes. $\mathrm{O}$ autor observa que no Brasil, a maior parte da repartição do ICMS entre os municípios, vai para os mais ricos; estes municípios têm maior força política, onde há um interesse maior dos governos em legislar favorecendo as indústrias, com concentração nas grandes cidades, já os pequenos municípios industriais, seriam beneficiados por políticas que propóem a desconcentração industrial. Conforme o autor, alguns municípios agem por conta própria, sem esperar que as iniciativas que lhes beneficiam partam dos Governos Estadual ou Federal (Souza, 2005).

No mesmo sentido, para Salto e Almeida (2016, p. 285-286) a democracia no Brasil está sendo construída de forma desigual, tanto nas diferenças de patrimônio e renda, quanto no acesso à justiça, nos serviços públicos, na educação, nas condiçóes econômicas e também no desenvolvimento regional. Ainda na visão de Salto e Almeida (2016, p. 202), "é necessário refletir sobre o papel do Estado em atuar com qualidade em suas atividades primordiais, como educação e infraestrutura, antes de expandir outras áreas; e a protelação delas só vai agravar o quadro do desenvolvimento econômico para as futuras geraçóes".

\subsection{GUERRA FISCAL}

Uma das questóes bastante discutidas no atual cenário político brasileiro é a "Guerra Fiscal". Trata-se de ações de governos estaduais com o objetivo de atrair investimentos privados para seu estado. Assim como em outros países, a utilização do instrumento fiscal para implantação de políticas de desenvolvimento regional é antigo (Dulci, 2002; Viana Junior; Caixe; Ponte, 2019; Loch et al., 2020).

A Constituição de 1988 atribuiu aos Estados e municípios o poder de decidir sobre suas receitas tributárias, havendo assim maior autonomia para os Estados legislarem sobre suas fontes de receitas. A partir desse período, os incentivos utilizados para acelerar o desenvolvimento dos Estados se tornaram mais comuns. Essa autonomia deu origem a disputa entre os Estados que ficou conhecida como "Guerra Fiscal", tendo como arma de negociação a arrecadação de tributos, como o ICMS (Nascimento, 2008).

De acordo com Lizote e Bidinha (2012, p. 6), os Estados com menor capacidade de arrecadação tributária e com o propósito de atrair novos investimentos para estimular o desenvolvimento local, disponibilizam benefícios no intuito de incentivar a importação de produtos e serviços por seu Estados.

Para Torres (2007, p. 77-78), um exemplo dos Estados que praticam o uso desses benefícios, é o Espírito Santo (com o FUNDAP) e Santa Catarina (com o PRÓ- 
EMPREGO). Para o autor, estes benefícios atraíram trading companies, que passaram a importar as mercadorias de seus clientes a partir desses Estados, mesmo estando os seus clientes localizados em outros Estados.

No início, a "Guerra Fiscal" era vista como alternativa dos Estados com menor poder aquisitivo em atrair investimentos, o que equilibrava a falta de uma política de desenvolvimento regional mais ativa. Com o tempo os Estados mais ricos começaram a praticar a "Guerra Fiscal" o que a enfraqueceu como instrumento de desenvolvimento regional e passou a motivar uma cadeia de distorçóes prejudiciais ao desenvolvimento do país (Viana, 2013).

Pois, devido aos resultados econômicos que os incentivos podem gerar para as empresas e deste que esses incentivos superem o custo da mudança (do Estado menor para o maior), o empresário poderá decidir se transferir para o Estado que conceder melhores benefícios fiscais (Gonçalves \& Ribeiro, 2013, p. 85).

Conforme citado por Chaves (2009, p. 9), os Estados que passaram a oferecer incentivos a importação, passaram a gerar mais empregos e, observou-se um aumento da renda per capita, contribuindo também para a diminuição das desigualdades regionais.

Já na visão de Nascimento (2008), os impactos das políticas de incentivos podem gerar efeitos positivos ou negativos; os positivos seriam o aumento de empregos e renda, o aumento do PIB estadual, assim como a futura receita tributária. Os negativos seriam o aumento da diferença no desenvolvimento entre os Estados e a perda de receita presente.

Sendo assim, na visão de Nascimento (2008, p. 680) o efeito da "Guerra Fiscal" incorpora políticas públicas por meio de benefícios fiscais e/ou financeiros, no qual buscam atrair desenvolvimento para um Estado em detrimento de outras unidades federativas, o que pode indicar que a "Guerra Fiscal" não é socialmente benéfica ao país visto como um todo.

Macedo e Angelis (2013, p. 188) afirmam que a "Guerra Fiscal" nos últimos vinte anos foi um elemento importante para a dinâmica regional do Brasil, pois muitas empresas bem-sucedidas instaladas nas regióes do Sul e Sudeste direcionaram suas aquisiçôes e investimentos para os Estados que ofereciam incentivos.

Em consequência da "Guerra Fiscal" se tem Estados com maior concentraçáo industrial e, consequentemente, Estados prejudicados com a diminuição de arrecadação de ICMS - notadamente São Paulo. Esses estados atuaram fortemente contra esta prática sob a argumentação de que o ICMS seria devido no Estado onde está localizado o destinatário final da mercadoria, e não no Estado onde está localizado o estabelecimento importador (Macedo \& Agelis, 2013, p. 185).

Diante de tal fato, a FIESP (Federação das Indústrias do Estado de Sáo Paulo) que desde 2011 organizava um conjunto de eventos para denunciar o efeito negativo dos incentivos concedidos às importaçôes por um grupo de Estados, além de descreverem o impacto resultante que poderia se esperar na estrutura produtiva da Federação: a desindustrialização. A FIESP conseguiu ser atendida em suas reivindicaçôes pela Resolução 13/2012. O fim dos incentivos viria para redirecionar as importaçóes do Brasil para o Sudeste, onde a maior parte do consumo acontece (Macedo \&Angelis, 2013, p. 186). 


\subsection{GUERRA FISCAL E A VISÃO EXTERNA}

Assim como no Brasil governos de alguns países têm atraído empresas, como montadoras de automóveis, que desenvolvem complexos industriais trazendo também para esse local várias empresas prestadoras de serviço. Para isso, utilizam-se de benefícios fiscais, treinamento de mão de obra, empréstimos subsidiados e instalação de infraestrutura para motivar a vinda dessas empresas para determinadas regióes (Souza, 2005).

Em certos países, como por exemplo, França e Canadá, os incentivos oferecidos às empresas motrizes nem sempre trazem o retorno esperado, uma vez que as novas empresas atraídas não incentivaram o desenvolvimento local, por que suas relaçóes comerciais de insumo e produto têm melhores resultados com a economia nacional (ou de outras regióes desse país) ou mesmo com o exterior (Polése, 1994, p. 95).

Nos EUA quando uma empresa multinacional quer investir, os estados competem pela empresa oferecendo reduçóes de impostos. Na verdade, esses incentivos estão vinculados ao uso de insumos internos pela empresa e, portanto, afetam as decisóes de produção. A competição reduz os impostos estaduais, mas em contrapartida pode reduzir a necessidade de subsídios federais. Portanto, a concorrência ou "guerra fiscal" nem sempre reduz o bem-estar nacional (Davies, 2005, p.498-512), sem considerar, obviamente, a questão do desequilíbrio econômico entre as regióes.

De acordo com pesquisa feita por Peter e Fischer (2004, p. 31-32), os incentivos fiscais nos Estados Unidos apresentaram um efeito positivo em 10\% dos casos. O autor afirma que os incentivos concedidos tinham um impacto apenas marginal na indução de postos de trabalho e novos investimentos, mas não foi possível afirmar que os incentivos fiscais não apresentaram impacto na economia. Peters e Fisher (2004, p. 31) afirmam ainda que o motivo pelo qual os incentivos nos Estados Unidos não terem um impacto mais positivo na determinação do crescimento econômico é devido ao fato desses incentivos fiscais não terem uma representação significativa no custo total das empresas.

No estudo de Bondonio e Greenbaum (2006) os autores recomendam que as políticas públicas com relação aos incentivos na Itália devam sempre estar com o foco em dois aspectos: na criação de estratégias para o desenvolvimento local e de novos empregos.

Peters e Fisher (2004, p. 32) concluem que não há uma resposta definitiva sobre a possibilidade dos Estados crescerem de forma mais acelerada com ou sem os incentivos fiscais. Além disso, foi verificado que a existência de vários incentivos fiscais em determinada regiâo está relacionada com uma fraca qualidade dos serviços públicos e, é importante frisar, que para as empresas é importante a oferta de serviços públicos de qualidade.

\subsection{INCENTIVOS FISCAIS}

Incentivos fiscais premiam as empresas, desonerando-as de tributos com o objetivo de estimular determinados comportamentos. Dessa forma, os incentivos fiscais direcionados à redução ou à exoneração do ICMS deram aos Estados o poder de atrair empresas para seus respectivos territórios (Campanelli, 2010, p. 73-117). 
Tanzi e Zee (2007, p.8) questionam a eficiência dos incentivos fiscais nos países em desenvolvimento, sobretudo quando não é utilizado nenhum critério para ser oferecido tal incentivo. Segundo os autores, seria interessante que os incentivos não fossem utilizados apenas como forma de atrair as empresas para um território.

Porsse (2005, p. 125) em estudo no Brasil evidencia os resultados econômicos gerados pelos incentivos adotados pelos Estados e acrescenta que no caso do Rio Grande do Sul houve um efeito positivo e negativo para os demais Estados.

Um dos mecanismos de incentivo que pode ser implementado pelos Estados diz respeito à importação. Cordeiro (2013, p. 19) descreve afirma inclusive que os Estados estão estariam desobedecendo as normas constitucionais na intenção de criar mais empregos e atrair mais recursos financeiros para seu território os Estados propiciam isençôes, incentivos fiscais para as importadoras localizadas em seu território. O Estado de Santa Catarina, por exemplo, implantou o Sistema PRÓ-EMPREGO, assumindo que as mercadorias direcionadas a comercialização, sem similar catarinense, recolham o ICMS de $3 \%$ da operação na importação. Diversos Estados também, como Goiás, Pernambuco, Paraná, Tocantins, Ceará, Piauí, Maranhão, Mato Grosso do Sul, Rio de Janeiro, Bahia, Sergipe e Espírito Santo, criaram incentivo à importação no país (Lizote \& Bidinha, 2012, p. 6).

\subsection{RESOLUÇÁO 13/2012 DO SENADO FEDERAL}

O Senado Federal em abril de 2012, implantou a Resoluçáo de no 13 . Com essa resolução as alíquotas interestaduais de ICMS que antes era 7\% e 12\% passaram a ser $4 \%$ (Becker, 2015, p. 13-14).

O senado decidiu que a alíquota de $4 \%$ incida sobre bens e produtos importados que, após seu desembaraço aduaneiro, ainda que submetidas aos processos de industrialização, ocorram em mercadorias ou bens que utilizam acima de $40 \%$ de matéria prima importada (Lizote \& Bidinha, 2012, p. 8).

Lizote e Bidinha (2012, p. 8) afirmam que a norma foi adotada para tentar manter um equilíbrio entre controlar a entrada de mercadorias importadas no país e evitar um prejuízo mais expressivo aos Estados, permitindo que mesmo com a diminuição da alíquota de ICMS, estes Estados continuem concedendo benefícios fiscais nas operaçóes destinadas a importaçáo. Os autores relatam ainda que, o principal o objetivo desta norma seria enfraquecer as vantagens competitivas das mercadorias importadas diante das nacionais e diminuir o efeito da "Guerra Fiscal" por conta de diferentes alíquotas interestaduais dos produtos importados.

Conforme Cordeiro (2013, p. 20), a Resoluçâo 13/2012 é uma forma de conter a concessão de benefícios no contexto da "Guerra Fiscal" como resultado de uma ação realizada por advogados, economistas e políticos que, segundo eles, a inconstitucionalidade destes benefícios causa prejuízo financeiro para outros Estados.

Fazem parte da Resolução 13/2012, os bens e as mercadorias que:

$\$ 1^{\circ} \mathrm{O}$ disposto neste artigo aplica-se aos bens e mercadorias importados do exterior que, após seu desembaraço aduaneiro: 
I - não tenham sido submetidos a processo de industrialização;

II - ainda que submetidos a qualquer processo de transformação, beneficiamento, montagem, acondicionamento, recondicionamento, renovaçáo ou recondicionamento, resultem em mercadorias ou bens com Conteúdo de Importação superior a 40\% (quarenta por cento) (Brasil, Resolução No13/2012, Art.1º).

Os bens e mercadorias que não fazem parte da Resolução 13/2012, são:

$\$ 4^{\circ} \mathrm{O}$ disposto nos $\$ 1^{\circ}$ e $\$ 2^{\circ}$ não se aplica:

I - aos bens e mercadorias importados do exterior que não tenham similar nacional, a serem definidos em lista a ser editada pelo Conselho de Ministros da Câmara de Comércio Exterior (Camex) para os fins desta Resolução;

II - aos bens produzidos em conformidade com os processos produtivos básicos de que tratam o Decreto-Lei no 288, de 28 de fevereiro de 1967, e as Leis n. ${ }^{\circ}$ 8.248, de 23 de outubro de 1991, 8.387, de 30 de dezembro de 1991, 10.176, de 11 de janeiro de 2001, e 11.484, de 31 de maio de 2007 (Brasil, Resolução No13/2012, Art.1).

Por outro lado, o Senador Ricardo Ferraço (PSDB-ES) iniciou uma ação jurídica para revogar a Resolução 13/2012. A medida foi citada em delação premiada pelo executivo Cláudio Melo Filho, ex-lobista da Odebrecht, como resultado de pagamento de propina a Senadores. De acordo com o Senador Ferraço, a Resolução 13/2012 causou prejuízos de R \$ 5 bilhóes ao Espírito Santo. Como a alíquota de ICMS interestadual foi a 4\%, o principal efeito da norma foi acabar com FUNDAP, criado no final do ano de 1960 (Canário, 2016).

\subsubsection{Consequências da Resoluçáo 13/2012 do Senado Federal}

Para alguns autores a implantação da Resoluçáo 13/2012 foi motivo de críticas sobre sua constitucionalidade. A medida do Senado estaria afetando o comércio nacional, comprometendo a eficiência do Congresso Nacional, sendo ele o responsável pela proteçáo do mercado interno (Cordeiro, 2013, p. 20). No mesmo sentido, Marques e Granado (2013, p. 71) concordam que a Resolução 13/2012 é inconstitucional, uma vez que a Constituiçáo Federal institui, em seu artigo 155, que os incentivos fiscais só podem ser disciplinados por meio de lei complementar.

Com a Resolução 13/2012, serão necessárias várias mudanças nas operaçóes realizadas por empresas com alteraçôes significativas em quase todas às áreas, compras, suprimentos, fiscal, contabilidade e comercial (Barros, 2013). Essas mudanças geraram resistência dos empresários por terem que divulgar informaçóes de custos, nas notas fiscais emitidas aos seus clientes. Outro questionamento foi devido ao tempo muito curto para implantação e dificuldade na interpretação da legislação (Molon, et al., 2013, p. 347).

Com a unificação do ICMS para os produtos importados, muitos estados criaram um decreto antecipando o diferencial de alíquota entre os Estados o que prejudicou, principalmente, as empresas do Simples Nacional, pois a diferença de alíquota passou a integrar seu custo, já que essas empresas não podem se creditar desse imposto. Sendo assim, com a alíquota única para todos os Estados, as empresas passaram a analisar melhor os custos referentes a transportes, e outros elementos como a eficiência e logística dos sistemas 
portuários, pois o gasto referente a condução da mercadoria do porto em que a mercadoria foi desembaraçada até o destino final, onera os resultados da empresa (Santos et al., 2013).

De acordo com Lizote e Bidinha (2012, p. 9), os municípios mais impactados com esta normativa foram: São Francisco do Sul, Navegantes, Imbituba, Itajaí e Itapoá e a maior perda seria para Santa Catarina, pois as empresas não poderão mais se beneficiar do PRÓEMPREGO (geração de emprego e renda no território catarinense por meio de tratamento tributário diferenciado do ICMS).

Lagemann (2014, p. 128) cita que, no Rio Grande do Sul, ao instituir a alíquota única interestadual de $4 \%$, as empresas varejistas do Simples Nacional, tentaram anular o Decreto que antecipa a diferença da alíquota interestadual.

Conforme Lizote e Bidinha (2012, p. 11), a Resolução 13/2012 não trará benefícios relevantes aos Estados concedentes de incentivos fiscais, um dos motivos, segundo as autoras, é que ocorrerá a migração de um grupo de importaçóes dos portos de alguns Estados para o porto de Santos em São Paulo, por ser maior porto alfandegário e ter a maior concentração industrial.

Joaquim (2011), conclui que a "Guerra Fiscal” poderá chegar ao fim, com a medida que unificará as alíquotas. Isso porque os custos de importar por São Paulo ainda é muito alto quando comparado com o Estado de Santa Catarina. Ao recolher 3\% de ICMS em Santa Catarina, e 21,95\% em São Paulo há uma diferença significativa. É provável que o impacto da medida seja menor para as empresas que importam insumos para produzir nos Estados que subsidiam a importação, e que o governo de Santa Catarina, providenciará medida que reduza o impacto (Joaquim, 2011, p. 21).

Salto e Almeida (2016, p. 287-288) são taxativos em afirmar que a medida com o propósito de acabar com a "Guerra Fiscal" que unificou a alíquota de ICMS não teve sucesso, da mesma forma que a medida em que os incentivos oferecidos pelos os estados seriam aprovados apenas se todos os secretários da fazenda das unidades da Federaçáo concordassem. Segundo os autores, o Governo Federal não tem créditos para oferecer algo que gere um certo equilíbrio aos impactados, pois não consegue oferecer infraestrutura a curto e médio prazo. Sem as vias de transportes, os estados com a economia ainda em desenvolvimento não conseguem competir de forma mais eficiente perdendo a chance de utilizar outras características econômicas importantes como, por exemplo: custo de terrenos e mão de obra mais baratos, restando assim o caminho da "Guerra Fiscal".

Salto e Almeida (2016, p. 287-288) ressaltam ainda que, a Lei Kandir também contribuiu para a falta de credibilidade do governo federal, devido alguns estados não terem se beneficiado com a desoneração das exportações, conforme foi instituído no dispositivo legal. Os autores justificam que com as despesas públicas sempre aumentando, resultante do conflito distributivo, sempre haverá o risco de promessas fracassadas pela próxima interferência orçamentária do governo nas compensações financeiras futuras. Apenas uma medida impactante, declarada pela Secretaria do Tesouro Federal, de cobrança retroativa sobre os benefícios ilegais poderia forçar as partes a chegarem a um acordo. Isso, contudo, não se fará sem atribuir perdas a alguns estados e deixar vestígios nas relaçóes políticas. 
Outro fato a ser tratado se refere a uma provável "inversão" na "Guerra Fiscal”. Antes eram credores de ICMS aqueles Estados que concediam isençóes e outros benefícios aos contribuintes importadores de produtos e serviços pelos seus territórios, agora, os valores de ICMS serão repassados aos Estados destinatários, deixando de entrar nos cofres dos Estados originários. Portanto, é questionado o fato de que os Estados remetentes em grande parte, não conseguirão competir com os Estados destinatários, pois esses possuem, de maneira geral, polos industriais e comerciais grandes (Amaral et al., 2013, p. 2).

De acordo com Cordeiro (2013, p. 7-8) existem duas vertentes que discutem a Resolução 13/2012:

\begin{abstract}
a primeira - listado pelo próprio Governo Federal e apoiado pelos grandes polos industriais brasileiros, como São Paulo - apoia a criação da Resoluçáo e o fim da "Guerra Fiscal" e a segunda - defendido pelos Estados concedentes - não concorda com o fim dos benefícios fiscais oriundos de mercadorias importadas. A vertente que apoia criação da Resolução e a unificação do ICMS na importação cita que tais benefícios fiscais são inconstitucionais, pois ferem os preceitos do artigo $2^{\circ}, \$ 2$ da lei no $24 / 1975$. Tal artigo cita que as isençóes, incentivos e benefícios são concedidos mediante deliberaçōes unânimes dos Estados; no entanto, percebe-se, claramente, que isto não estava acontecendo, afinal, os incentivos fiscais criados pelos Estados não são aceitos pela totalidade dos entes da Federação.
\end{abstract}

Em seu estudo, Lagemann (2014, p. 129) conclui que a Resolução 13/2012, está tomando à direçâo de uma reforma tributária que, "ameniza a situaçáo da "Guerra Fiscal" de "luta por receitas" e reduz a disputa pela produçáo de bens nacional frente às forças de produção internacional.

Para Joaquim (2011, p. 20) "a festa acabou" na medida em que um importador transferia suas instalaçôes para outro Estado com o intuito único de redução de custo tributário, náo observando a infraestrutura da regiáo e o tempo que percorreria para alcançar o mercado consumidor. Joaquim (2011) relata ainda que, deixa de existir a vantagem que algumas empresas possuíam, incentivos para importadoras e/ou trading companies, que trabalhavam somente como intermediários para venda de produtos em outros Estados.

Conforme resultado da pesquisa, Becker (2015, p. 22-25), ao contrário do que era previsto pelo governo do Estado de Santa Catarina, constatou um aumento na importaçáo após a Resolução 13/2012. O estudo evidenciou aumento nas importaçóes em 2013 e demonstrou que a redução da alíquota de ICMS para acabar com as importaçóes por esses Estados náo se mostrou eficiente. Assim também, conforme apresentado em seu estudo, o desemprego e a arrecadação do ICMS não foi afetada. Becker (2015) conclui que as importaçóes através de Santa Catarina, e do Brasil, dependem menos dos benefícios fiscais do que o que se acreditava. Contudo, a dinâmica cambial tem mais poder na decisão de importar ou exportar.

Conforme o trabalho de Souza e Ávila (2015), a resolução 13/2012 afetou também no recolhimento do ICMS por substituição tributária, antecipação de impostos e diferencial de alíquota. Em sua pesquisa, através de uma análise de compra e venda antes e após a resolução, o autor identificou que as empresas do Simples nacional ou com incidência de 
substituição tributária, passaram a pagar mais impostos e para o autor esse foi o real motivo para a unificação da alíquota de ICMS a 4\%.

Já no Espírito Santo, o sistema Fundap não acabou quando foi implantada a Resolução, mas os resultados apresentados na pesquisa de Zonta, et al. (2013), demonstraram que a queda na receita de ICMS relativa ao sistema impactou significativamente as finanças dos municípios, acarretando, por consequência, impactos significativos na região metropolitana.

Para Folloni e Vosgerau (2016) a eficácia da Resolução 13/2012, deve ser analisada de forma crítica. Para o autor, é possível afirmar que "Guerra fiscal" não prejudicou significativamente a arrecadação do ICMS no país. O objetivo da resolução de acabar com a "Guerra Fiscal”, que estaria causando sérios prejuízos para desenvolvimento econômico do país, portanto, poderia ser substituído por novos métodos de fiscalização que seriam capazes em contribuir mais para o aumento da arrecadação.

Como pode ser observado, não há uma concordância entre os autores e as entidades que avaliaram as consequências da implantação da Resolução 13/2012. Observa-se duas linhas de pensamento: os que acham favorável os efeitos econômicos da norma para a sociedade e para o Estado; e os que apontam diversos problemas para economia do país como um todo.

\subsection{INDICADORES ECONÔMICOS}

Para analisar o impacto gerado pela Resolução 13/2012 do Senado Federal que unificou a alíquota de $4 \%$ do ICMS interestadual na comercialização dos produtos importados ou bens com "Conteúdo de Importação" superior a 40\% (quarenta por cento) será utilizado o PIB per capita como indicador econômico de avaliação de impacto.

O PIB per capita foi selecionado com base na revisão da literatura que o indica para avaliar esse tipo de impacto. De acordo com Furtuoso e Guilhoto (2003, p. 806), o PIB é um indicador econômico essencial para subsidiar informação para a economia como um todo e também para tomadores de decisão no âmbito privado e governamental, ele demonstra o valor de toda a riqueza gerada em um determinado local ou país, sendo formado pelo conjunto de todos os bens e serviços finais produzidos durante certo período de tempo.

Conforme destaca Rossetti (2002, p. 594) o PIB é o resultado final das atividades econômicas de produção realizada dentro do território econômico do país, não incluídas as transaçóes intermediárias. A taxa de crescimento do PIB sinaliza um dos mais importantes objetivos da política macroeconômica: a expansão da oferta agregada de bens e serviços (Rossetti , 2002, p. 726).

Folloni e Vosgerau (2016, p. 503) afirmam que a desigualdade regional no país pode ser observada a partir da análise da distribuição PIB nacional entre as regióes do país. A regiâo sudeste é responsável por mais de $55 \%$ do PIB total, o que incentivou a inclusão do art. 151, I, da Constituição Federal, que permite aos Estados, "a concessão de incentivos fiscais propostos a promoverem o equilíbrio do desenvolvimento socioeconômico no país". 
De acordo Weschenfelder (2013, p. 14), alguns estados preveem prejuízos na economia interna com a entrada em vigor da Resolução no 13/2012, com a alíquota interestadual de ICMS a 4\%, os principais aspectos a serem monitorados ou esperado são: aumento do incentivo à importação, enfraquecimento da indústria brasileira, redução do número de empregos no mercado interno, diminuição da competitividade dos produtos nacionais e, como consequência, redução no PIB. Diante disso, avaliou-se nesse trabalho a seguinte hipótese de pesquisa:

Hipotese 1: A Resoluçáo do Senado Federal 13/2012 diminuiu o resultado econômico nos Estados que concedem incentivos fiscais na importação.

\section{METODOLOGIA}

\subsection{COLETA DOS DADOS E DEFINIÇÁO DA AMOSTRA}

Nessa pesquisa, separou-se os Estados que não possuem nenhum incentivo (grupo de controle) daqueles Estados que concedem algum tipo de incentivo (grupo de tratamento), quando separado o grupo de tratamento do grupo de controle, conforme dados extraídos do IBGE, a Tabela 1 mostra que o PIB nos estados que pertencem ao grupo de tratamento, ou seja, os Estados que de alguma forma concedem incentivos, corresponde em média 40\% do PIB total do país.

Tabela 1 - Comparativo PIB 2009 a 2016

\begin{tabular}{|c|c|c|c|c|c|c|c|c|c|}
\hline \multirow{15}{*}{ 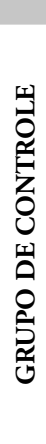 } & UF & 2009 & 2010 & 2011 & 2012 & 2013 & 2014 & 2015 & 2016 \\
\hline & AC & 7.408 & 8.342 & 8.949 & 10.138 & 11.474 & 13.459 & 13.622 & 13.751 \\
\hline & AL & 24.182 & 27.133 & 31.657 & 34.650 & 37.283 & 40.975 & 46.364 & 49.456 \\
\hline & AM & 50.560 & 60.877 & 70.734 & 72.243 & 83.051 & 86.669 & 86.560 & 89.017 \\
\hline & $\mathrm{AP}$ & 7.491 & 8.238 & 9.409 & 11.131 & 12.763 & 13.400 & 13.861 & 14.339 \\
\hline & DF & 124.324 & 144.174 & 154.569 & 164.101 & 175.907 & 197.432 & 215.613 & 235.497 \\
\hline & MG & 287.444 & 351.123 & 400.125 & 442.283 & 488.005 & 516.634 & 519.326 & 544.634 \\
\hline & MT & 52.693 & 56.601 & 69.154 & 79.666 & 89.213 & 101.235 & 107.418 & 123.834 \\
\hline & PA & 61.665 & 82.685 & 98.711 & 107.081 & 121.225 & 124.585 & 130.883 & 138.068 \\
\hline & $\mathrm{PB}$ & 30.230 & 33.522 & 37.109 & 42.488 & 46.377 & 52.936 & 56.140 & 59.089 \\
\hline & RN & 30.941 & 36.185 & 40.993 & 46.412 & 51.518 & 54.023 & 57.250 & 59.661 \\
\hline & RO & 19.725 & 23.908 & 27.575 & 30.113 & 31.121 & 34.031 & 36.563 & 39.451 \\
\hline & RR & 5.672 & 6.639 & 7.304 & 7.711 & 9.011 & 9.744 & 10.354 & 11.011 \\
\hline & RS & 204.345 & 241.249 & 265.056 & 287.587 & 332.293 & 357.816 & 381.985 & 408.645 \\
\hline & SP & 1.127 .094 & 1.294 .696 & 1.436 .673 & 1.559 .033 & 1.715 .238 & 1.858 .196 & 1.939 .890 & 2.038 .005 \\
\hline \multirow{18}{*}{ 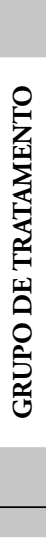 } & & 2.033 .774 & 2.375 .372 & 2.658 .018 & 2.894 .638 & 3.204 .480 & 3.461 .135 & 3.615 .831 & 3.824 .459 \\
\hline & & $61,02 \%$ & $61,13 \%$ & $60,74 \%$ & $60,12 \%$ & $60,10 \%$ & $59,89 \%$ & $60,31 \%$ & $61,02 \%$ \\
\hline & BA & 137.942 & 154.420 & 166.603 & 182.573 & 204.844 & 223.930 & 245.025 & 258.649 \\
\hline & CE & 67.200 & 79.336 & 89.696 & 96.974 & 109.037 & 126.054 & 130.621 & 138.379 \\
\hline & ES & 69.215 & 85.310 & 105.976 & 116.851 & 117.274 & 128.784 & 120.363 & 109.227 \\
\hline & GO & 92.866 & 106.770 & 121.297 & 138.758 & 151.300 & 165.015 & 173.632 & 181.692 \\
\hline & MA & 40.995 & 46.310 & 52.144 & 60.490 & 67.695 & 76.842 & 78.475 & 85.286 \\
\hline & MS & 39.518 & 47.271 & 55.133 & 62.013 & 69.203 & 78.950 & 83.082 & 91.866 \\
\hline & PE & 79.761 & 97.190 & 110.162 & 127.989 & 141.150 & 155.143 & 156.955 & 167.290 \\
\hline & PI & 18.946 & 22.269 & 25.941 & 28.638 & 31.284 & 37.723 & 39.148 & 41.406 \\
\hline & PR & 196.676 & 225.205 & 257.122 & 285.620 & 333.481 & 348.084 & 376.960 & 401.662 \\
\hline & RJ & 391.651 & 449.858 & 512.768 & 574.885 & 628.226 & 671.077 & 659.137 & 640.186 \\
\hline & SC & 129.099 & 153.726 & 174.068 & 191.795 & 214.512 & 242.553 & 249.073 & 256.661 \\
\hline & SE & 21.707 & 26.405 & 29.108 & 32.853 & 35.336 & 37.472 & 38.554 & 38.867 \\
\hline & TO & 13.690 & 16.405 & 18.346 & 20.684 & 23.797 & 26.189 & 28.930 & 31.576 \\
\hline & & 1.299 .265 & 1.510 .475 & 1.718 .364 & 1.920 .122 & 2.127 .139 & 2.317 .818 & 2.379.956 & 2.442 .746 \\
\hline & & $38,98 \%$ & $38,87 \%$ & $39,26 \%$ & $39,88 \%$ & $39,90 \%$ & $40,11 \%$ & $39,69 \%$ & $38,98 \%$ \\
\hline & & 3.333 .039 & 3.885 .847 & 4.376 .382 & 4.814 .760 & 5.331 .619 & 5.778 .953 & 5.995 .787 & 6.267 .205 \\
\hline
\end{tabular}

Nota: PIB de 2010 a 2016 deflacionado pelo IPCA como referência o ano de 2009.

Fonte: IBGE (2016). 
A análise desenvolvida foi do tipo quantitativa. A amostra foi constituída por 27 Estados, no qual 13 concedem incentivos fiscais e/ou financeiros considerados grupo de tratamento - Santa Catarina, Paraná, Goiás, Pernambuco, Tocantins, Ceará, Piauí, Rio de Janeiro, Mato Grosso do Sul, Maranhão, Sergipe, Bahia e Espírito Santo.

Os demais Estados (14) foram considerados no grupo de controle - Acre, Alagoas, Amazonas, Amapá, Distrito Federal, Minas Gerais, Mato Grosso, Pará, Paraíba, Rio Grande do Norte, Roraima, Rio Grande do Sul e São Paulo - que não concedem incentivos semelhantes.

A amostra foi delineada com informações PIB per capita, no período de 2009 a 2016. O Quadro 1 exibe a descriçáo e as respectivas fontes de coleta desses indicadores - variáveis.

Quadro 1 - Fonte de coleta dos dados e classificação das variáveis

\begin{tabular}{|c|c|c|c|}
\hline Tipo & Código & Descriçáo/Classificaçáo & Fonte de coleta \\
\hline $\begin{array}{l}\text { Variável } \\
\text { auxiliar }\end{array}$ & População total & $\begin{array}{l}\text { Total de habitantes por } \\
\text { estado }\end{array}$ & $\begin{array}{c}\text { Instituto Brasileiro de } \\
\text { Geografia e Estatística (IBGE) }\end{array}$ \\
\hline $\begin{array}{l}\text { Variável } \\
\text { dependente }\end{array}$ & PIB per capita & $\begin{array}{c}\text { Produção interna bruta } \\
\text { dividido pelo total de } \\
\text { habitantes }\end{array}$ & $\begin{array}{c}2009 \text { a } 2016 \text { - Instituto } \\
\text { Brasileiro de Geografia e } \\
\text { Estatísticas (IBGE) }\end{array}$ \\
\hline \multirow{2}{*}{$\begin{array}{c}\text { Variável } \\
\text { independente } \\
\text { (Proxy) }\end{array}$} & Grupo & $\begin{array}{l}1 \text { - se o Estado concede } \\
\text { incentivos fiscais e/ou } \\
\text { financeiros e } 0 \text { - caso } \\
\text { contrário }\end{array}$ & não aplica \\
\hline & Tempo & $\begin{array}{l}1 \text { - Após a Resolução } \\
\text { 13/2012 (2013 a 2016) } \\
\text { e } 0 \text { - Antes a Resolução } \\
\text { 13/2012 (2009 e 2012) }\end{array}$ & não aplica \\
\hline
\end{tabular}

Os dados foram tabulados e posteriormente, importados para software Stata ${ }^{\circledR} 12$, que foi utilizado nas análises da estatística descritiva e estimação do modelo estatístico.

\subsection{MODELO ESTATÍSTICO}

Para determinar a existência e a significância da relação estatística, foi adotado o modelo econométrico denominado de Diference-in-Diference, apresentado em Wooldridge (2001). O modelo compara as diferenças dos indicadores entre grupos de Estados. O modelo busca descrever o impacto da ocorrência de um fator externo altera que altera o cenário atual onde as empresas, as cidades e pessoas atuam e avalia a diferença desse impacto entre o grupo de controle e o grupo de tratamento. Conforme o autor afirma é preciso que os dois grupos tenham sido expostos ao evento.

O presente estudo tem como propósito avaliar se a decisão do senado em aprovar a resolução 13/2012 gerou benefícios econômicos aos Estados ou não. Para tal finalidade, utiliza-se um modelo matemático que gere evidências estatísticas, corroborando assim, com 
conhecimentos até então, não comprovados, referente a decisão do senado pela aprovação da resolução.

Como afirma Heij et al. (2004), "os modelos econométricos ajudam a compreender a relação entre as variáveis econômicas e de negócios e avalia os possíveis efeitos das decisões”, ou seja, por meio da modelo regressão múltipla proposto adiante, será possível avaliar estatisticamente se a decisão do senado em aprovar a resolução contribui ou não para desenvolvimento dos estados medidos pelas proxies utilizadas nesse estudo.

Nascimento (2008) fez uma análise comparativa similar entre os Estados participantes e não participantes da "Guerra Fiscal", contudo, em um cenário em que não existia a Resolução 13/2012 do Senado Federal.

A finalidade é avaliar as mudanças na variável dependente como resposta a mudanças na variável independentes (Hair Jr. et al., 2005). Logo, a estimativa dos resultados da alteração feitas pela Resolução e o desempenho dos estados serão avaliados por meio do modelo proposto a seguir:

$$
\begin{array}{r}
Y_{i t}=\beta_{0}+\beta_{1} \text { Tempo }_{i t}+\beta_{2} \text { Grupo }_{i t}+\beta_{3}(\text { Tempo } * \text { Grupo })_{i t} \\
+\beta_{4 t} \text { DummyAno }_{t}+\beta_{5 k} \text { DummyEstado }_{i}+\varepsilon_{i t}
\end{array}
$$

Onde:

$\boldsymbol{Y}_{i t}$ é o PIB per capita do $i$-ésimo estado no ano $t$;

Tempo - Representa a variável binária definida como um (1) - Após a Resolução 13/2012 (2013 a 2016) e 0 - Antes a Resolução 13/2012 (2009 e 2012);

Grupo - Representa a variável binária definida como um 1 - se o í-ésimo Estado concede incentivos fiscais e/ou financeiros e 0 - caso contrário;

Tempo*Grupo - Representa a variável interação binária entre Tempo e Grupo definida como um 1 - se o í-ésimo Estado concede incentivos fiscais e/ou financeiros no período após a resolução 13/2012 e 0 - caso contrário;

DummyAno $_{\boldsymbol{t}}$ - Essa variável foi acrescentada ao modelo para controlar o efeito por ano no que diz respeito a variável dependente (por exemplo: tendência);

DummyEstado $_{i}$ - Essa variável foi acrescentada ao modelo para controlar o efeito por estado no que diz respeito a variável dependente (por exemplo: diferenças quanto ao porte, economia, etc.);

$\varepsilon_{i t}$ - Representa o erro aleatório.

Assim sendo, o coeficiente considerado mais importante na equação acima é $\boldsymbol{\beta}_{3}$, que exibe a diferença na variável dependente entre os Estados que concedem incentivos fiscais após a resolução 13/2012- tratamento, comparado os Estados que não concedem incentivos - grupo controle. Por exemplo, supondo que coeficiente estimado $\widehat{\boldsymbol{\beta}_{3}}$ associado a variável dependente PIB per capita, apresentasse uma estimativa negativa com valor igual a 100, sendo este significativo ao um nível de significância específico. Esses resultados indicariam que após resolução (a partir de 2013), o PIB per capita do grupo tratamento reduziu em média em $\mathrm{R} \$ 100,00$ quando comparado ao grupo controle, ou seja, em tese o grupo tratamento teria sido impactado economicamente após a resolução 13/2012. 


\section{ANÁLISE DOS DADOS}

\subsection{ESTATÍSTIVA DESCRITIVA}

Inicialmente, faz-se a caracterização da amostra por grupo, onde se segmentou os indicadores para o período antes e após a resolução 13/2012, em seguida, exibem os resultados das regressóes estimadas.

Com a finalidade de entender a distribuição do PIB por grupo, no período considerado, a Tabela 1 apresenta a média dos indicadores por grupo - antes (2009 a 2012) e após (2013 a 2016).

A utilização do PIB, como já explicado, foi incluída com propósito de representar o desenvolvimento econômico dos estados por grupos. Pressupóe-se que, com a criação da Resolução 13/2012, o indicador PIB de algum modo foi impactado. Sendo assim, para aferir e evidenciar estatisticamente a hipótese, foi estimado o modelo empírico proposto na subseção 3.2 .

$\mathrm{Na}$ tabela 2 é possível observar que o crescimento do PIB ocorreu tanto no grupo de controle quanto no de tratamento. Contudo, observa-se que o PIB per capita teve um crescimento maior nesse período nos estados que compóem o grupos de controle. No período analisado essa diferença de crescimento entre esses dois grupos de Estados chegou a $26,47 \%$ de diferença.

Antes da resolução, a média do PIB per capita dos Estados do grupo de controle chegava a 16.608 , ou seja, $58 \%$ da média per capita dos estados do grupo de controle. Após a resolução, a média percapita do grupo de controle chega a 54\% do PIB percapita dos Estratos do grupo de controle. Uma redução de 4 pontos percentuais.

Tabela 2 - Estatística descritiva do PIB per capita antes e após a resolução 13/2012

\begin{tabular}{ccccccccc}
\hline & \multicolumn{9}{c}{ Resolução 13/2012 } & & $\begin{array}{c}\text { Variação } \\
\text { da Média }\end{array}$ \\
\cline { 3 - 9 } & & \multicolumn{4}{c}{ Antes } & \multicolumn{3}{c}{ Após } \\
\hline \multirow{2}{*}{ Variável } & Grupo & N & Média & $\begin{array}{c}\text { Desvio } \\
\text { Padrão }\end{array}$ & N & Média & $\begin{array}{c}\text { Desvio } \\
\text { Padrão }\end{array}$ \\
\hline PIB per capita & Controle & 56 & 28.604 & 36.176 & 56 & 40.899 & 51.251 & $43 \%$ \\
\hline & Tratamento & 52 & 16.608 & 7.823 & 52 & 22.323 & 9.324 & $34 \%$ \\
\hline & Total Geral & 108 & 22.828 & 27.168 & 108 & 31.955 & 38.452 & $40 \%$ \\
\hline
\end{tabular}

Nota: Antes - período de 2009 a 2012; e após - período de 2013 e 2016.

Fonte: Elaborado pelos autores.

Obviamente, não se pode atribuir exclusivamente à resolução em análise essa piora no resultado econômico dos Estados do grupo de tratamento. Entretanto, é um indicativo de que esse período trouxe uma piora relativa do resultado econômico para esses Estados. No tópico seguinte, busca-se isolar a variável indicativa da resolução 13/2012. 


\subsection{MODELO DE REGRESSÁO}

Tendo como objetivo principal avaliar se houve impactos econômicos nos Estados após a resolução. A Tabela 3 exibe os resultados deste modelo e as respectivas estatísticas.

Tabela 3 - Estatísticas das Regressóes Estimadas

\begin{tabular}{c|c|c|c}
\hline Variável independente & Descriçáo & \multicolumn{2}{|c}{ Variável Dependente } \\
\hline \multirow{2}{*}{ Proxy } & & \multicolumn{2}{|c}{ PIB per capita } \\
\cline { 3 - 4 } & Constante $\left(\boldsymbol{\beta}_{0}\right)$ & 5263,68 & \multicolumn{1}{|c}{0,027} \\
\hline \multirow{2}{*}{ Dummys $(1)$} & $\operatorname{Tempo}\left(\boldsymbol{\beta}_{1}\right)$ & 17183,41 & $0,000^{* * *}$ \\
& $\operatorname{Grupo}\left(\boldsymbol{\beta}_{2}\right)$ & 4554,20 & $0,095^{*}$ \\
& Tempo*Grupo $\left(\boldsymbol{\beta}_{3}\right)$ & $-6580,22$ & $0,047^{* *}$ \\
\hline \multirow{2}{*}{ Estatísticas } & Ano & \multicolumn{2}{|c}{} \\
& Estado & \multicolumn{2}{|c}{} \\
& Estatística F & $71,55^{* * *}$ & \\
& $\mathrm{R}^{2}$ ajustado & $88,25 \%$ & \\
& $\mathrm{~N}$ & 216 & \\
\hline
\end{tabular}

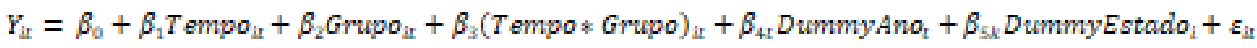

Nota: (1) Variável acrescentada ao modelo para controlar o efeito ano e estado respectivamente;(2) Para os coeficientes destacados ${ }^{* * *},{ }^{* *} \mathrm{e}^{*}$ é significativo ao nível de $1 \%, 5 \%$ e $10 \%$.

Fonte: Elaborado pelos autores.

No que concerne à hipótese de pesquisa deste estudo, o coeficiente $\boldsymbol{\beta}_{3}$, ao nível de significância de até $5 \%$, evidencia que o grupo de tratamento foi impactado significativamente e negativamente após a resolução 13/2012.

A metodologia proposta gerou evidências estatísticas que permitem confirmar a hipótese tratada nesse estudo. No que tange a hipótese aventada nesse estudo, os resultados corroboram, parcialmente, com o autor Weschenfelder (2013) que acreditava que reduzindo a alíquota de ICMS dos produtos importados, poderia diminuir a competitividade dos produtos nacionais, impactando no PIB nacional, isso não foi possível ser observado nos resultados, em especial no que se refere ao crescimento do PIB nessas regióes. Todavia, quando se observa os Estados do grupo de controle percebe-se que o impacto foi negativo para os seus PIB per capita. Como apresentado pelo autor Joaquim (2011, p. 20), a vantagem que os estados que concediam incentivos deixou de existir com a medida. Isso pode ser o resultado direto das empresas, atraídas pelo incentivo, terem retornado ao seu estado de origem.

Por outro lado, mediante os resultados apresentados na pesquisa, não se pode afirmar conforme Becker (2015) que as importaçôes do Brasil, dependem menos dos benefícios fiscais do que o informado pelos opositores aos incentivos. 


\section{CONSIDERAÇÓES FINAIS}

Esta pesquisa analisou o impacto da unificação das alíquotas interestadual de ICMS a 4\%, na situação econômica dos Estados que teve início 01 de janeiro de 2013 após a medida que implantou a Resolução 13/2012. Para responder a pergunta da pesquisa, foi realizado um estudo de caráter exploratório e descritivo. Foi utilizado o modelo econométrico, denominado Diference-in-Diference que confronta as alteraçóes nas variáveis entre os períodos e entre os Estados, antes e após a Resolução 13/2012 do Senado Federal.

Os resultados evidenciam que após a resolução 13/2012 o PIB foi impactado negativamente nos estados que concedem incentivos à importação, embora tenha ocorrido um aumento no PIB per capita desses Estados em comparação ao período anterior mas, quando comparado ao grupo de controle, percebe-se que esse crescimento foi menor do que o percebido no grupo de controle. Dessa forma, é possível inferir que em um cenário sem a resolução os estados que ofereciam incentivos a importação poderiam ter um avanço mais positivo em relação ao PIB per capita.

A eficiência da Resolução 13/2012 deve ser analisada com parcimônia, não podendo assim concluir se a mesma foi benéfica ou não. É possível que os estados que se sentiram prejudicados começaram a adotar outras medidas para evitar o efeito negativo da resolução. Muitos estados começaram a cobrar, por exemplo, a antecipação da diferença do imposto dos produtos importados, prejudicando principalmente as empresas do Simples Nacional, que tiveram que repassar essa diferença para seus custos, visto que essas empresas não têm o crédito desse imposto. Sendo assim, a disputa entre os estados podem tomar outro rumo, as empresas passaram a analisar melhor os custos de transportes, pois, com a alíquota única para todos os Estados, o transporte da mercadoria do porto de desembaraço aduaneiro até o destino final passou a onerar os lucros da empresa importadora sem a compensaçáo dos incentivos (Santos et al., 2013).

A proposta da Resolução 13/2012 são polêmicas e complexas de serem avaliadas, em especial poque geram açóes dos governantes para atenuá-las, mas, sem dúvida produziram efeitos econômicos para a atividade empresarial de forma significativa. Sem contar com o aspecto de que a medida sofre com grandes debates em relação a sua adequação à Constituiçăo.

Um aprofundamento do estudo poderia ser analisado levando em consideração outras variáveis de controle para explicar aspectos não tratados. Sugere-se fazer comparaçóes entre os estados e qual medidas os estados passaram a tomar após resoluçáo.

\section{REFERÊNCIAS}

Almeida, Alexandre Fernando de; Silva, Laércio Baptista. Governo Federal fixa a alíquota de ICMS interestadual em 4\% para os produtos importados, independente do Estado da federação e tenta acabar com a Guerra Fiscal entre os portos. Revista de Administraçáo do UNISAL, Campinas, v.3, p. 47-62, Jan/Abril 2013.

Almeida, Cristina Beatriz de Souza; Queiroz, Renata Correa. Guerra dos Portos: Alíquota Interestadual para Produtos Importados de 4\%. 1ª edição, IOB FOLHAMATIC, 2013. 
Amaral, Gilberto Luiz do. et al. Guerra dos Portos e Resolução 13 do Senado

- Esclarecimentos úteis em relaçáo à unificaçáo do ICMS de importados.

Disponível em: <http://www.ibpt.com.br/img/uploads/novelty/estudo/475/

IcmsunificadoFabioINTEGR AL.pdf>. Acesso em: 13 mar. 2016.

Barquero, Antônio Vázquez. Desenvolvimento endógeno em tempos de globalização. Porto Alegre: Editora da UFRGS e FEE - Fundação de Economia e Estatística (Governo do RS), 2002.

Barros, Gustavo Ferreira. Efeitos práticos da Resolução no 13/2012 do Senado no diaa-dia das empresas. 2013. Disponível em: <http://www.fiscosoft.com.br/main_artigos_ index.php? PID=281603\&printpage=_>. Acesso em: 05 mai. 2016.

Becker, Mario José Lima. Os efeitos da Resoluçáo 13/2012 do Senado Federal da República sobre o setor importador de Santa Catarina, Balneário Camburiú, SC, 2015.

Bondonio, Daniele; Greenbaum, Robert T. Do Local tax incentives affect economic growth? What mean impacts miss in the analysis of enterprise zone policies? Regional Science and Urban Economics, v. 37, n. 1, p. 121-136, 2007.

Brasil. Congresso. Senado. Resoluçáo no 13, de 25 de abril de 2012. Diário Oficial da União, Brasília, DF, 26 abr. 2012. Seção 1, p. 1-2

Brasil.Constituição da República Federativa do Brasil de 1988. 35ª Edição. São Paulo: Saraiva, 2005.

Brasil. Decreto n. 3.847, de 30 de mar. de 2017. IPI incidente sobre os produtos que menciona, Brasília, DF, mar 2017.

Brasil. Lei no 6668 de 15 de maio de 2001. Altera a redaçáo do artigo $4^{\circ}$ da Lei no 2.508, de 22.5.1970, suas alteraçóes posteriores, e dá outras providências. Disponível em: <http://www3.al.es.gov.br/>. Acesso em: 05 mar. 2016.

Brasil. Lei Complementar no 24, de 07 de janeiro de 1975. Dispóe sobre os convênios para a concessáo de isençóes do imposto sobre operaçóes relativas à circulaçáo de mercadorias, e dá outras providências. Disponível em: <http://www.planalto.gov.br/ ccivil_03/LEIS/LCP/Lcp24.htm>. Acesso em: 05 mar. 2013.

Brasil. Resolução 13, de 26 de abril de 2012. Estabelece alíquotas do Imposto sobre Operaçóes Relativas à Circulaçáo de Mercadorias e sobre Prestaçáo de Serviços de Transporte Interestadual e Intermunicipal e de Comunicaçáo (ICMS), nas operaçóes interestaduais com bens e mercadorias importados do exterior. Disponível em: <http://www.planalto.gov.br/ccivil_03/_Ato2011-2014/2012/Congresso/RSF-132012. htm> Acesso em: 15 fev. 2016. 
Campanelli, Daniela Moreira. Incentivos tributários estaduais concedidos

unilateralmente e segurança jurídica. 2010. Dissertação (Mestrado em Direito)Pontifícia Universidade Católica de São Paulo (PUC- SP), São Paulo, 2010.

Canário, Pedro. Revista Consultor Jurídico. Brasília.12 de dezembro de 2016. Disponível em: <https://www.conjur.com.br/2016-dez-12/senador-tenta-anular-resolucao-segundodelator-foi-comprada>. Acesso: 07 mar. 2018.

Chaves, Vinícius Figueiredo. O ICMS e a Guerra Fiscal entre os Estados. Revista da EMERJ, v. 12, n. 48, p. 202-227, 2009.

Cordeiro, Gustavo Fernande. Guerra dos Portos Resoluçáo 13 do Senado Federal. Dissertação (Mestrado em Direito)- Faculdade FUMEC- Belo Horizonte, 2013.

Davies, Ronald B. State tax competition for foreign direct investment: a winnable war? Journal of International Economics, v. 67, n. 2, p. 498-512, 2005.

Dulci, Otávio Soares. Guerra fiscal, desenvolvimento desigual e relaçóes federativas no Brasil. Revista de Sociologia e Política, n. 18, p. 95-107, Jun. 2002.

Folloni; André, Vosgerau; Douglas Ramos. Impactos da Guerra Fiscal do ICMS e da Resolução no 13/2012 do Senado Federal sobre a ordem econômica. Economic Analysis of Law Review, v. 7, n. 2, 2016.

Furtuoso, Maria Cristina Ortiz; Guilhoto, Joaquim José Martins.Estimativa e mensuração do Produto Interno Bruto do Agronegócio da Economia Brasileira, 1994 a 2000. Revista de Economia e Sociologia Rural, v. 41, n. 4, p. 803-827, 2003.

Gonçalves, Oksandro Osdival; Ribeiro, Marcelo Miranda. Os incentivos fiscais sob a perspectiva da Análise Econômica do Direito. Economic Analysis of Law Review, Brasília, v. 4, n. 1, p. 79-102, jan./jun. 2013.

Hair, Jr., Joseph F.; Anderson, Rolph E.; Tatham, Ronald L.; Black, William C. Análise Multivariada de dados. Tradução: Adonai Schlup Sant'Anna e Anselmo Chaves Neto. 5. ed. Porto Alegre: Bookman. p. 593, 2005.

Heij, Christiaan et al. Econometric methods with applications in business and economics. Oxford University Press, 2004.

IBGE, Instituto Brasileiro de Geografia e Estatística. Disponível em: <http://www.ibge. gov.br/>. Acesso em: 26 ago. 2016.

Joaquim, Patrícia. Acabou a Festa. CRN Brasil entrevista/ Especial Guerra Fiscal. Revista CRN, 1a quinzena de Setembro 2011 p. 18-20. 
Lagemann, Eugenio. A "guerra fiscal dos portos" e a Resolução 13/12 do Senado Federal: abrangência, efeitos e perspectivas. Indicadores Econômicos FEE, v. 41, n. 3, 2014.

Lima, Ana Carolina da Cruz; Lima, João Policarpo Rodrigues. Programas de desenvolvimento local na regiáo Nordeste do Brasil: uma avaliação preliminar da guerra fiscal. Revista Economia e Sociedade, Campinas, v. 19, n. 3, p. 557-588, 2010.

Lizote, Suzete Antonieta; Bidinha, Eleine Renata. Guerra Fiscal dos Portos: um Estudo sobre o Impacto da Unificação do ICMS Interestadual em 4\% para Produtos Importados no Estado de Santa Catarina. In: IX SIMPÓSIO DE EXCELÊNCIA EM GESTÃO E TECNOLOGIA, 9., Rio de Janeiro, 2012. Anais... Rio de Janeiro, 2012

Loch, Murialdo et al. The Government as Shareholder and Principal-Principal Conflicts in the Brazilian Electric Power Industry. Brazilian Business Review, v. 17, n. 1, p. 24-45, 2020 .

Macedo, Fernando Cezar de; Angelis, Ângelo. Guerra Fiscal dos Portos e Desenvolvimento Regional no Brasil. REDES- Revista Desenvolvimento Regional, Santa Cruz do Sul, v. 18, n. 1, p. 185-212, jan/ abril 2013.

Marques, Alexsandra; Granado, Emerson de Morais. A inconstitucionalidade da Resoluçấo no 13/2012 do Senado Federal que limita a alíquota do ICMS na Importação.

Revista Eletrônica de Iniciaçáo Científica, v.4, n.1, p. 59-73, 2013. Disponível em: $<$ www.univali.br/ricc->.

Molon, Aline et al. Procedimentos para adequaçáo das empresas do Rio Grande do Sul às Normas da Resolução 13/2012. In: SEMINÁRIO DE INICIAÇÃO CIENTÍFICA CURSO DE CIÊNCIAS CONTÁBEIS DA FSG, 7., Caxias do Sul/ RS, 2013. Anais... Caxias do Sul, 2013.

Nascimento, Sidnei Pereira do. Guerra Fiscal: uma avaliação entre alguns Estados participantes e não participantes. Economia Aplicada, v. 12, n. 4, 2008.

Pereira; Luiz Carlos Bresser. Os dois métodos e o núcleo duro da Teoria Econômica. Revista de Economia Política, v. 29, n. 2, pp. 163-190, abril- junho/ 2009.

Peters, A.; Fisher, P. The failures of economics development incentives. Journal of the American Planning Association, Chicago, v. 70, n.1, p. 27-37, 2004.

Polése, Mario. Économie urbaine et régionale. Paris: Econômica, 1994.

Porsse, A. A. Competiçáo tributária regional, externalidades fiscais e federalismo no Brasil: uma abordagem de equilíbrio geral computável. Tese doutorado. UFRGS, 2005.

Rossetti, J. P. Introduçáo à economia. 19. ed. São Paulo: Atlas, 2002. 
Salto, Felipe; Almeida, Mansueto. Finanças Públicas, da Contabilidade criativa ao resgate da credibilidade. 1. ed. São Paulo: Record, 2016.

Santos, Dieine da Silva dos et. al. Aplicação da resolução do senado federal 13/2012 em uma industria do simples nacional e suas consequências. In: SEMINÁRIO DE INICIAÇÃO CIENTÍFICA CURSO DE CIÊNCIAS CONTÁBEIS DA FSG, 7., [s.l.], 2013. Anais... [s.1.], 2013.

Santos, Gilberto Álvares; Machado, Ilonka de Paula. Planejamento de Importação: Aspectos Jurídicos, Fiscais e Tributários. In: SEMINÁRIO DE ADUANEIRAS, CURSOS E TREINAMENTOS, 2011, Vila Velha (ES). Anais... Vila Velha: ACT, 2011.

Souza, Nali de Jesus de. Teoria dos Polos, Regióes Inteligentes e Sistemas Regionais de Inovação. Análise, Porto Alegre, v. 16, n. 1, p. 87-112, jan./jul. 2005.

Souza, Vitor Márcio de; ÁVILA, Lucimar Antônio Cabral de. Impactos da Redução do ICMS para Produtos Importados em Empresas Mineiras do Lucro Real e Simples Nacional. In: CONGRESSO DE CONTABILIDADE, Santa Catarina, 2015. Anais... Santa Catarina, 2015.

Torres, Ricardo Lobo. O Princípio da isonomia, os incentivos do ICMS e a jurisprudência do STF sobre a guerra fiscal. Incentivos fiscais: questóes pontuais nas esferas federal, estadual e municipal. São Paulo: MP Editora, 2007.

Viana, Emanuel Lucas Costa. D21 23 - A Inconstitucionalidade da Guerra Fiscal Relativa a Arrecadação de ICMS. Revista Eletrônica de Direito. Outubro de 2013.

Viana Junior, Dante Baiardo C. Cavalcante; Caixe, Daniel Ferreira; Ponte, Vera Rodrigues Maria Rodrigues. Moderating effect of economic instability in the relationship between concentration of control and market value: empirical evidence in Latin America. BBR. Brazilian Business Review, v. 16, n. 4, p. 400-415, 2019.

Weschenfelder, Daniel Henrique. A Guerra dos portos: Resolução no 13 de 2012 do Senado Federal e suas consequências. In: CONGRESSO DE PESQUISA E EXTENSÃO DA FSG, Caxias do Sul, RS, 2013. Anais... 2013.

Wooldridge, J. Econometric analysis of cross section and panel data. Cambridge: The MIT Press, p. 735, 2001.

Zonta, Neuza Duque; et al. O Impacto da Resoluçáo no 13/2012 do Senado Federal no Sistema FUNDAP e suas Consequências nas Finanças dos Municípios da Grande Vitória. SAPIENTIA - PIO XII n.12 Novembro/2013. 